\title{
Removal of heavy metals in electroplating wastewater by powdered activated carbon (PAC) and sodium diethyldithiocarbamate-modified PAC
}

\author{
Tae-Kyoung Kim¹, Taeyeon Kim², Woo-Seok Choe', Moon-Kyung Kim², Yong-Jun Jung ${ }^{3}$, \\ Kyung-Duk Zoh ${ }^{1^{+}}$ \\ ${ }^{1}$ Department of Environmental Health Sciences, School of Public Health, Seoul National University, Seoul 08826, Republic of Korea \\ ${ }^{2}$ Institute of Health \& Environment, Seoul National University, Seoul 08826, Republic of Korea \\ ${ }^{3}$ Department of Environmental Engineering, College of Applied Science, Catholic University of Pusan, Busan 46252, Republic of Korea
}

\begin{abstract}
We investigated simultaneous removal of heavy metals such as $\mathrm{Cr}, \mathrm{Ni}$, and $\mathrm{Zn}$ by adsorption onto powdered activated carbon (PAC) and PAC modified with sodium diethyldithiocarbamate (PAC-SDDC). Modification of PAC was confirmed by Fourier transform infrared spectroscopy and Scanning electron microscopy and energy dispersive X-ray spectroscopy. Both PAC and PAC-SDDC reached adsorption equilibrium within $48 \mathrm{~h}$, and the adsorption kinetics followed a pseudo-second order reaction kinetics. The removal of metals was enhanced with increasing both adsorbent dosage and followed the descending order of $\mathrm{Cr}>\mathrm{Ni}>\mathrm{Zn}$ for PAC and $\mathrm{Cr}>\mathrm{Zn}>\mathrm{Ni}$ for PAC-SDDC, respectively. Adsorption kinetics followed pseudo-second order kinetics. Adsorption kinetic results were well fitted by the Freundlich isotherm except for $\mathrm{Cr}$ adsorption onto PAC. The optimum $\mathrm{pH}$ for heavy metal adsorption onto PAC was 5, whereas that for PAC-SDDC ranged from 7 to 9, indicating that modification of PAC with SDDC significantly enhanced heavy metal adsorption, especially under neutral and alkaline $\mathrm{pH}$ conditions. Our results imply that SDDC modified PAC can be applied to effectively remove heavy metals especially Cr in plating wastewaters without adjusting $\mathrm{pH}$ from alkaline to neutral.
\end{abstract}

Keywords: Activated carbon, Adsorption, Heavy metals, Isotherm, Kinetics, Sodium diethyldithiocarbamate

\section{Introduction}

Industrial wastewater discharge usually contains toxic and harmful substances that can have negative effects on human health and aquatic ecosystems. Every year, large amounts of wastewater containing cyanide $\left(\mathrm{CN}^{-}\right)$and heavy metals are discharged from alloy, automobile-manufacturing, mining-processing, and metal-plating industries [1, 2]. Metal finishing and electroplating manufacturing units are the major sources of these contaminants, which contribute considerably to the environmental risk and pollution load of the receiving water system and its surroundings [3]. Therefore, the presence of heavy metals (Cr, Ni, and $\mathrm{Zn}$ ) in such effluents must be controlled, because these contaminants cause environmental problems due to their high toxicity even at low concentrations [4].

For metal-plating wastewater containing heavy metals, precipitation method is the most widely used conventional treatment process [5]. Most widely used conventional method is precipitation include hydroxide precipitation, and coagulation/flocculation [6]. Among the three aforementioned methods, hydroxide precipitation is the most commonly used because it is a cost effective method for reducing heavy metal concentrations to low levels, and can be easily handled. However, this method does not completely remove metals and produce a huge amount of toxic sludge that needs additional treatment processes [7]. For these reasons, as alternatives to precipitation method, various techniques have been employed including ion-exchange resin, reverse osmosis, electrocoagulation, and adsorption [8]. Except for adsorption, 
those methods can reduce metal ion, however, these methods also have limitations due to high operational cost [6, 8, 9]. Recently, adsorption has recognized as an economical and efficient method for removing heavy metals from polluted waters [10-12].

Even though adsorption is effective in removing heavy metals, but not as effective in removing organic compounds. Hence, various modification of adsorbent has been studied to increase heavy metal removal from water $[10,12,13]$. Among the modification functional groups, dithiocarbamate derivatives can improve metal adsorption abilities by metal ligand formation [13-16]. These dithiocarbamate molecules with large hydrophobic groups strongly adsorb heavy metals to the surface and can modify the characteristics of metal adsorbent to more favorable adsorption conditions [16]. Among the dithiocarbamate derivatives, Monser and Adhoum [17] used sodium diethyldithiocarbamate (SDDC) in the fixed bed modified granular activated carbon (GAC) column. Due to the attachment of SDDC, affinities between heavy metals $(\mathrm{Cu}$, $\mathrm{Zn}$ ) and the surfaces of GAC were improved [17]. SDDC was also applied as chelating agent in multi-walled carbon nanotubes as adsorbent for solid phase extraction prior to high performance liquid chromatography (HPLC) to measure Ni, cobalt (Co) and mercury $(\mathrm{Hg})$ ions in water samples [18].

Therefore, in this study, as an alternative to conventional treatment methods for removing heavy metals from metal-plating wastewater such as precipitation, we investigated the adsorption of $\mathrm{Cr}, \mathrm{Zn}$, and Ni by powdered activated carbon (PAC) and PAC modified with SDDC (PAC-SDDC). We examined the adsorption characteristics of $\mathrm{Cr}, \mathrm{Zn}$, and Ni using PAC and PAC-SDDC by determining the adsorption kinetics and isotherms of each adsorbent. We also investigate the effect of initial $\mathrm{pH}$ for removal of metals into each adsorbent. Finally, we proposed metal removal mechanism by PAC and PAC-SDDC based on the obtained results.

\section{Materials and Methods}

\subsection{Materials}

Commercially available PAC (Shinki Chemical, South Korea) was used as an adsorbent for PAC and PAC-SDDC. The characteristics of PAC are shown in Table 1. SDDC was used (Sigma-Aldrich, USA) to create the modified PAC; Table S1 in Supplementary Materials shows the structure and physicochemical properties of SDDC. A multi-element calibration

Table 1. Characteristics of PAC and SDDC Modified PAC (PAC-SDDC)

\begin{tabular}{lcc}
\hline \multicolumn{1}{c}{ Adsorbent } & PAC & PAC-SDDC \\
\hline Zeta potential $(\mathrm{mV})$ & -26.5 & -35.8 \\
Surface area $\left(\mathrm{m}^{2} \mathrm{~g}^{-1}\right)$ & 945 & 844 \\
Pore volume $\left(\mathrm{cm}^{2} \mathrm{~g}^{-1}\right)$ & 0.52 & 0.47 \\
Pore size $(\AA)$ & 21.9 & 22.2 \\
Bulk density & 2.28 & 1.87 \\
$\mathrm{pH}_{\text {pzc }}$ & 10.70 & 8.53 \\
\hline
\end{tabular}

PAC: powdered activated carbon; SDDC: sodium diethyldithiocarbamate standard solution dissolved in 5\% nitric acid was purchased from Perkin Elmer (USA), and $\mathrm{ZnSO}_{4} \cdot \mathrm{H}_{2} \mathrm{O}, \mathrm{K}_{2} \mathrm{Cr}_{2} \mathrm{O}_{7}$, and $\mathrm{NiSO}_{4} \cdot 7 \mathrm{H}_{2} \mathrm{O}$ were used for the experiments (Sigma-Aldrich, USA). Trace amounts of $1 \mathrm{~N} \mathrm{NaOH}$ or $\mathrm{H}_{2} \mathrm{SO}_{4}$ (Sigma-Aldrich, USA) were used to alter the initial $\mathrm{pH}$ of the artificial wastewater. Each solution was prepared with deionized water (Millipore, USA).

\subsection{PAC Modification with SDDC}

A 12-g sample of dried PAC was mixed with $250 \mathrm{~mL}$ of 5.30 $\mathrm{mmol} / \mathrm{L}$ SDDC solution in a water bath at $50^{\circ} \mathrm{C}$ at a stirring speed of $200 \mathrm{rpm}$ for $3 \mathrm{~d}$ [17, 19]. After this treatment, the mixture was filtered through a $0.45-\mu \mathrm{m}$ membrane filter (A045A047A, ADVANTEC, Japan) to separate the sorbent, then washed with distilled water. The SDDC-modified PAC was then oven dried at $100^{\circ} \mathrm{C}$ for $12 \mathrm{~h}$. Both adsorbents were dried at $100^{\circ} \mathrm{C}$ for $8 \mathrm{~h}$ before use.

\subsection{Characterization of PAC and Modified PAC (PAC-SDDC)}

Scanning electron microscopy (SEM; JSM-7610F, JEOL, USA) and energy dispersive X-ray spectroscopy (EDS; X-MAX 50, Oxford, UK) were used to check the chemical properties and morphology of the adsorbents. To measure the specific surface area of the adsorbents, a surface area analyzer (ASAP 2420, Micrometrics, USA) was used with gaseous nitrogen for surface probing via the Brunauer-Emmett-Teller (BET) method. Zeta analyzer (ELSZ-1000, Photal Otsuka Electronics, Japan) were used to investigate the surface charges of the adsorbents. The functional groups on the surfaces of the adsorbents were analyzed by Fourier transform infrared spectroscopy (FT-IR; VERTEX80v, Bruker, USA). The $\mathrm{pH}_{\mathrm{pzc}}$ values (point of zero charge) were obtained using the $\mathrm{pH}$ drift method [20]. The specific physicochemical properties of each adsorbent are listed in Table 1.

\subsection{Adsorption Experiment}

To examine the effect of time and initial $\mathrm{pH}$ on heavy metal adsorption, bench-scale and batch adsorption experiments were conducted. The initial concentration of each metal (Cr, Ni, and $\mathrm{Zn}$ ) was set to $50 \mathrm{mg} / \mathrm{L}$ in the distilled water samples by adding stock solution. PAC and PAC-SDDC containing $30 \mathrm{~g} / \mathrm{L}$ at $\mathrm{pH}$ 5 to 11 were injected into the artificial heavy-metal wastewater samples. After injection, the samples were agitated at a constant speed of $50 \mathrm{rpm}$ during the reaction. At the final step of the experiment, the samples were collected from the flasks and analyzed. The conditions for the adsorption experiments are summarized in Table S2.

The adsorption capacity $q_{e}(\mathrm{mg} / \mathrm{g})$ at equilibrium was calculated as follows;

$$
q_{e}=\frac{\left(c_{o}-c_{e}\right) V}{M}
$$

where $q_{e}$ is the adsorption capacities of heavy metal after reached adsorption equilibrium (mg adsorbate/g adsorbent), $V$ is the water volume $(\mathrm{mL}), C_{0}$ is the initial concentration 
of heavy metals $(\mathrm{mg} / \mathrm{L})$, and $C_{e}$ is the residual concentrations of 3 metals $(\mathrm{mg} / \mathrm{L})$.

To investigate the effect of adsorbent dosage on heavy metal adsorption of PAC and PAC-SDDC and to determine the isotherms, adsorption experiments were conducted individually, with $\mathrm{pH}$ dosage adjustment. The total volume of each test sample was $40 \mathrm{~mL}$ along with 5, 10, 15, 20, 25, 30, and $35 \mathrm{~g} / \mathrm{L}$ of PAC and PAC-SDDC. At the first step of the experiments, concentration of 3 metals was set at $50 \mathrm{mg} / \mathrm{L}$, and the initial $\mathrm{pH}$ was set to 7.0. All samples collected from each experiment were filtered with membrane filter $(0.45 \mu \mathrm{m}$, A045A047A, ADVANTEC, Japan), then were diluted before analysis.

\subsection{Isotherm}

The Freundlich adsorption isotherm applies to adsorption on non-specific and heterogeneous sites on solid surfaces and reportedly well fits heavy metal adsorption results, compared with the Langmuir isotherm [21]. Hence, the isotherm results were fitted to the Freundlich isotherm (Eq. (2)). The relevant equation for the adsorption model is as follows:

$$
q_{e}=K_{f} C_{e}^{\frac{1}{n}}
$$

where $C_{e}$ is the equilibrated concentration $(\mathrm{mg} / \mathrm{L}), 1 / n$ is the Freundlich intensity parameter, and $K_{f}$ is the Freundlich adsorption coefficient $\left((\mathrm{mg} / \mathrm{g})(\mathrm{mg} / \mathrm{L})^{-(1 / \mathrm{n})}\right)$, respectively.

\subsection{Analysis of Heavy Metal}

Inductively coupled plasma-mass spectrometry (ICP-MS, NEXION 350 D, Perkin Elmer, USA) was used to analyze the concentration of $\mathrm{Cr}, \mathrm{Ni}$, and $\mathrm{Zn}$ in diluted samples. Table S3 shows the QA/QC data.

\section{Results and Discussion}

\subsection{Characterization of PAC and PAC-SDDC}

First, the physicochemical characteristics of each adsorbent were examined. Fig. 1 shows SEM images and EDS patterns of the prepared adsorbents. While the surface of the PAC-only adsorbent was solely composed of carbon, whereas PAC-SDDC consisted of carbon and various inorganic elements (Fig. 1). After modification with SDDC, sulfur in SDDC compound was present on the PAC-SDDC surface. This result implies that SDDC was successfully adsorbed to the PAC surface.

Fig. 2 shows the FT-IR spectrum of each adsorbent; the main FT-IR spectra peak positions of PAC-SDDC showed a $\mathrm{C}=\mathrm{S}$ band in the range of $950-1,040 \mathrm{~cm}^{-1}$ and a $\mathrm{C}=\mathrm{N}$ band in the range of $1,460-1,550 \mathrm{~cm}^{-1}$, indicating that the modification of PAC with SDDC was successful. The FT-IR spectra of the adsorbents were in agreement with previous researches [16, 22, 23].

The physicochemical properties of each adsorbent are shown in Table 1. The surface area of PAC-SDDC measured using a

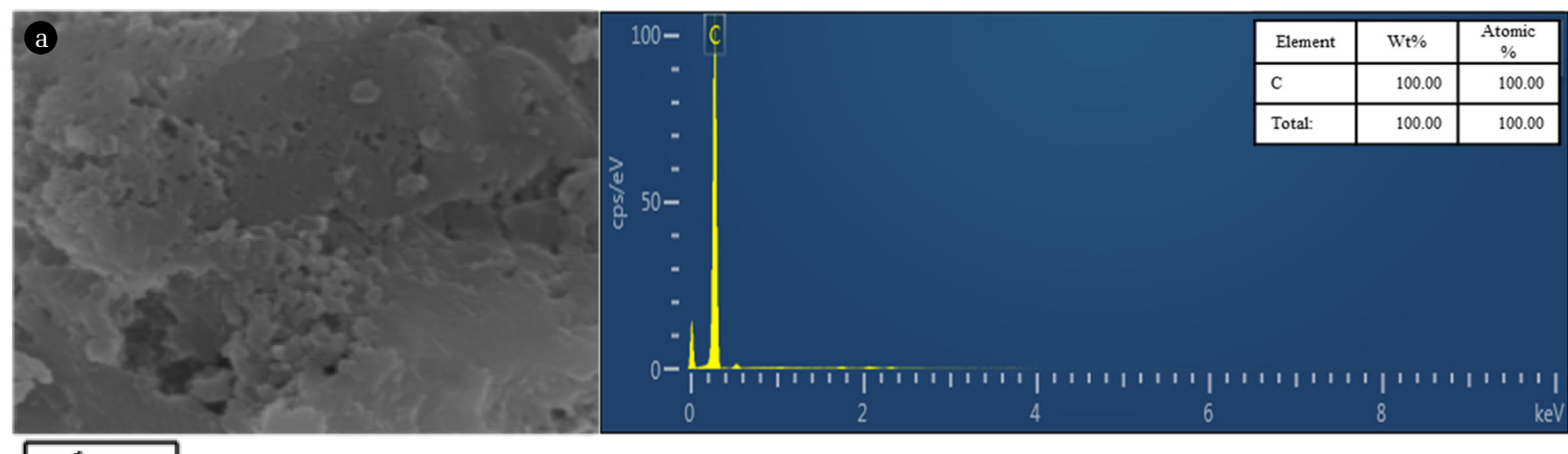

\section{$1 \mu \mathrm{m}$}

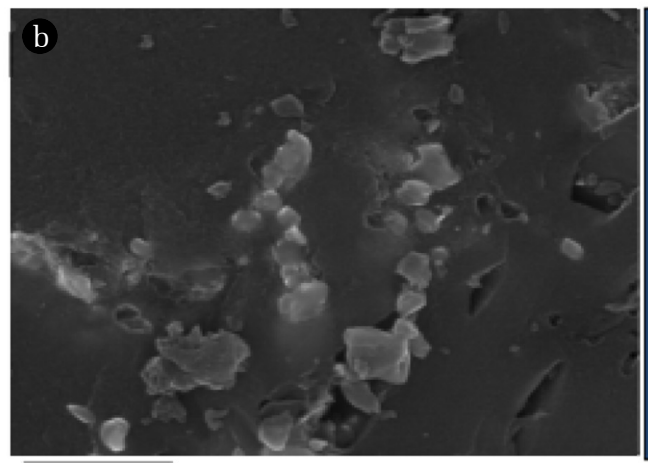

$2.5 \mu \mathrm{m}$

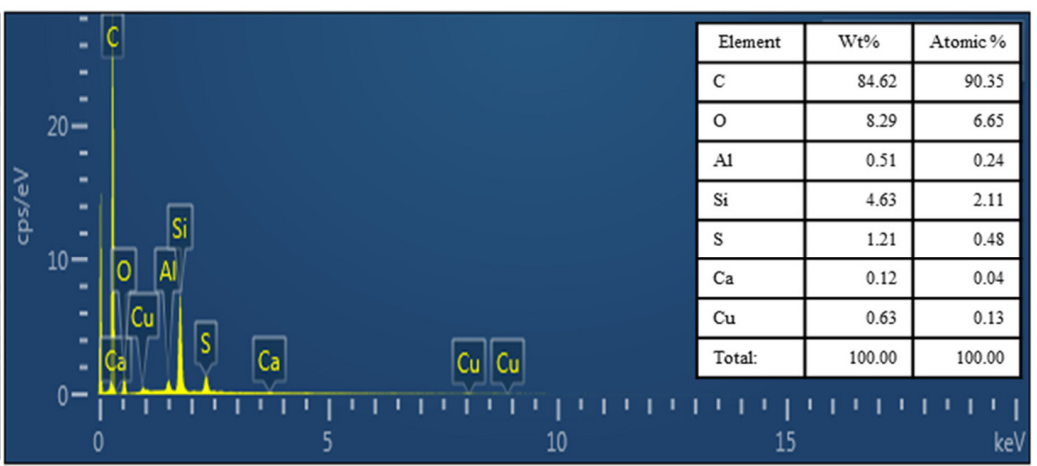

10

Fig. 1. SEM images and EDS patterns of (a) PAC and (b) PAC-SDDC. 


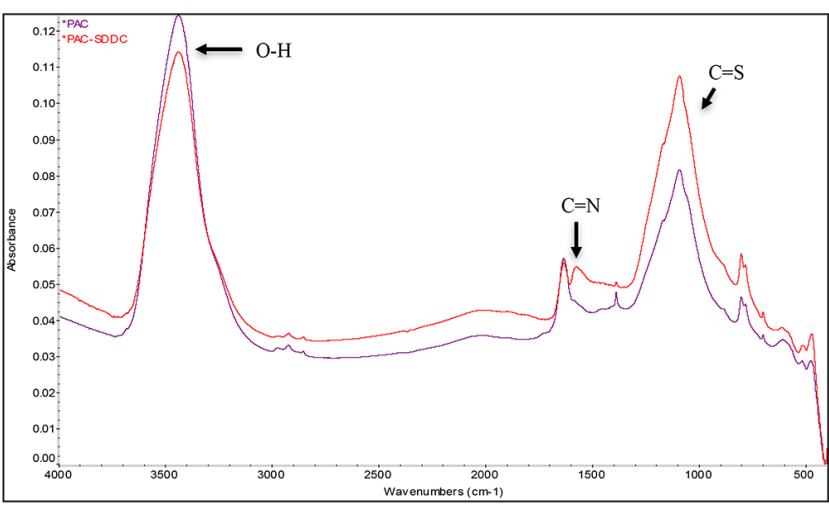

Fig. 2. FT-IR spectrum of PAC and PAC-SDDC.

surface analyzer decreased slightly from 945 to $844 \mathrm{~m}^{2} \mathrm{~g}^{-1}$ after modification of PAC; the bulk density also decreased from 2.28 to 1.87 . However, the pore volume and pore size did not change significantly. Interestingly, the $\mathrm{pH}_{\mathrm{pzc}}$ value, the $\mathrm{pH}$ where the electrical charge density of the surface is zero, decreased from 10.7 for PAC to 8.53 for PAC-SDDC. It was reported that the decrease in $\mathrm{pH}_{\mathrm{pzc}}$ value can be achieved by the increase in the acidic functional group [24]. In fact, the $\mathrm{pK}_{\mathrm{a}}$ of dithiol group in SDDC is known as 2.0 [25], thus the decrease in $\mathrm{pH}_{\mathrm{pzc}}$ values in PAC-SDDC imply that the acidic moiety increased on the PAC surface such as sodium dithiocarbamate group present in SDDC.

The zeta potential of PAC-SDDC also decreased compared to that of PAC (Table 1). It has been reported that the lower the carboxylic group, the lower the zeta potential value [24]. In addition, FT-IR measurement also indicates that reduction of $\mathrm{OH}$ functional group in carboxylic group $(-\mathrm{COOH})$ of PAC due to SDDC attachment on adsorbent.

\subsection{Adsorption Kinetics}

The effect of time during competitive metal removal kinetics by PAC and PAC-SDDC was measured. Fig. 3 shows the effect

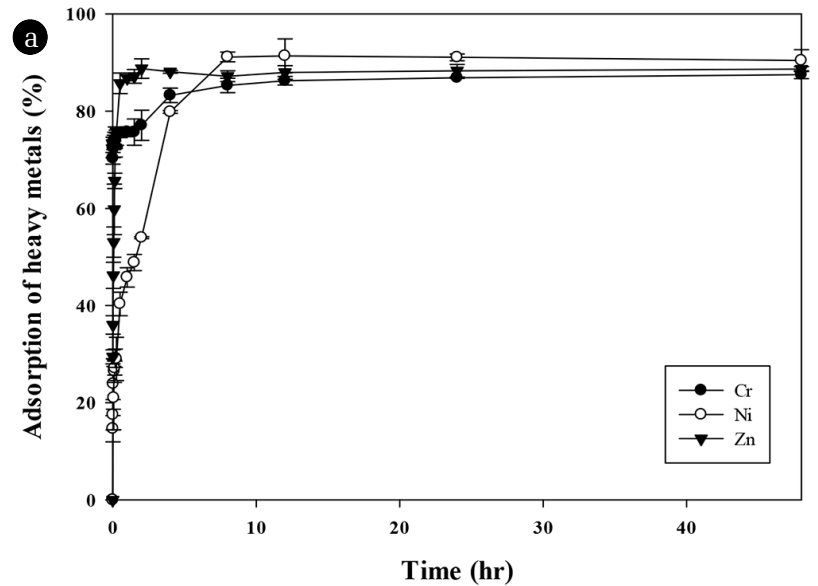

of time on heavy metal adsorption using PAC and PAC-SDDC. The optimal time for heavy metal adsorption on PAC was 8 $\mathrm{h}$ and for PAC-SDDC was increased to approximately $12 \mathrm{~h}$ (Fig. 3). In addition, $\mathrm{Zn}$ showed the highest adsorption rate on PAC followed by $\mathrm{Cr}$, then $\mathrm{Ni}$. In contrast, $\mathrm{Cr}$ showed the highest adsorption rate on PAC-SDDC followed by Zn, then Ni (Fig. 3). Gomes et al. [25] reported that heavy-metal adsorption competition sequences were variable, but statistically the most common sequence was $\mathrm{Cr}$, followed by $\mathrm{Zn}$, then $\mathrm{Ni}$. In this study, PAC did not follow this rule while PAC-SDDC did. There was no clear rationale for this phenomenon and further study is needed.

The adsorption kinetics of activated carbon can be fitted to a pseudo-first order equation (Eq. (3) and (4)) and a pseudo-second order equation (Eq. (4) and (6)) [26, 27]. The pseudo-first-order equation (Eq. (3)) describes the adsorption of activated carbon based on the metal concentration and the adsorption quantity of the activated carbon:

$$
\begin{gathered}
\frac{d q}{d t}=K_{1}\left(q_{e}-q_{t}\right) \\
\ln \left(q_{e}-q_{t}\right)=\ln q_{e}-K_{1} t
\end{gathered}
$$

where $q_{e}$ and $q_{t}$ are the adsorption capacities (mg/g) at equilibrium and at time $t$, respectively. The pseudo-first-order rate constant $\left(\mathrm{min}^{-1}\right)$ can be obtained by plotting a graph of $\ln \left(q_{e}-q_{t}\right)$ versus time.

In contrast, the rate of the pseudo-second-order reaction depends on the amount of heavy metal adsorbed on the adsorbent. The pseudo-second-order model is described by Eq. (5) and (6)

$$
\begin{aligned}
& \frac{d q}{d t}=K_{2}\left(q_{e}-q_{t}\right)^{2} \\
& \frac{t}{q_{t}}=\frac{1}{K_{2} q e^{2}}+\frac{t}{q_{e}}
\end{aligned}
$$

where, $K_{2}$ is the pseudo-second-order rate constant $(\mathrm{g} / \mathrm{mg} / \mathrm{min})$

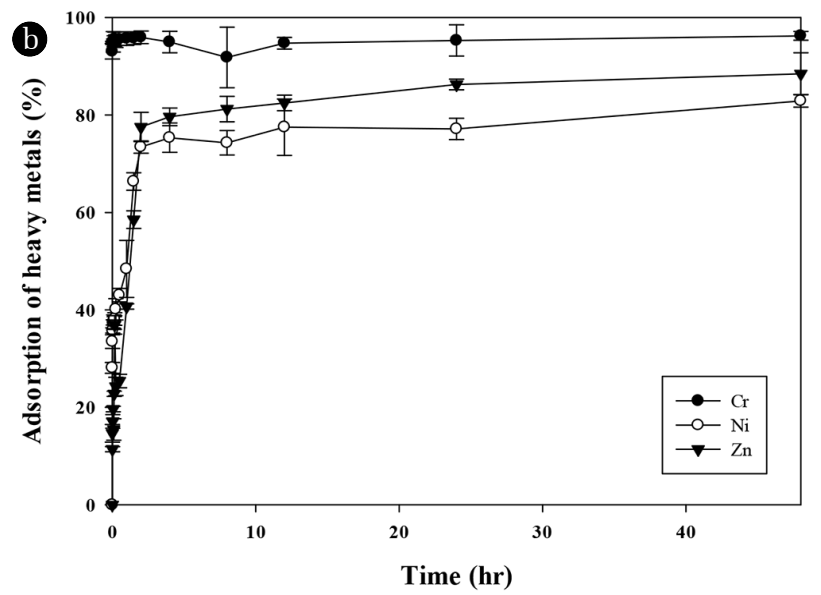

Fig. 3. Effect of time on the adsorption removal of heavy metals using (a) PAC and (b) PAC-SDDC $\left(\left[\mathrm{C}_{0}\right]=50 \mathrm{mg} / \mathrm{L} ; \mathrm{pH}=7.0 ;\right.$ temperature $=25^{\circ} \mathrm{C}$; time $=0-48 \mathrm{~h} ;[\mathrm{PAC}]$ and $[\mathrm{PAC}-\mathrm{SDDC}]=30 \mathrm{~g} / \mathrm{L} ; \mathrm{n}=3$ ). 
Table 2. Adsorption Kinetics Rate Constants and $\mathrm{R}^{2}$ Values of 3 Metals on PAC and PAC-SDDC $\left(\left[\mathrm{C}_{0}\right]=50 \mathrm{mg} / \mathrm{L} ; \mathrm{pH}=7.0 ;\right.$ temperature $=$ $25^{\circ} \mathrm{C}$; time $=0.5-120 \mathrm{~min} ;[\mathrm{PAC}]$ and $\left.[\mathrm{PAC}-\mathrm{SDDC}]=30 \mathrm{~g} / \mathrm{L}\right)$

\begin{tabular}{|c|c|c|c|c|c|}
\hline \multirow{2}{*}{ Adsorbent } & \multirow{2}{*}{ Metal } & \multicolumn{2}{|c|}{ Pseudo first-order kinetics } & \multicolumn{2}{|c|}{ Pseudo second-order kinetics } \\
\hline & & $K_{1}\left(\min ^{-1}\right)$ & $\mathbf{R}^{2}$ & $K_{2}(g /(m g \cdot \min ))$ & $\mathbf{R}^{2}$ \\
\hline \multirow{3}{*}{ PAC } & $\mathrm{Cr}$ & 0.035 & 0.502 & 0.789 & 1.000 \\
\hline & $\mathrm{Ni}$ & 0.023 & 0.933 & 1.119 & 0.988 \\
\hline & $\mathrm{Zn}$ & 0.044 & 0.822 & 0.669 & 0.999 \\
\hline \multirow{3}{*}{ PAC-SDDC } & $\mathrm{Cr}$ & 0.024 & 0.332 & 0.626 & 1.000 \\
\hline & $\mathrm{Ni}$ & 0.015 & 0.351 & 0.825 & 0.974 \\
\hline & $\mathrm{Zn}$ & 0.012 & 0.847 & 0.813 & 0.961 \\
\hline
\end{tabular}

and can be obtained by plotting a graph of $t / q_{e}$ versus $t$.

The adsorption kinetic results are shown in Table 2 and Fig. S1; both PAC and PAC-SDDC adsorbents were well fitted into the pseudo-second order equation. Several researches reported that fitting to the pseudo-second order equation imply that adsorption processes are governed by chemisorption [28, 29].

\subsection{Effect of Adsorbent Dosage}

The role of adsorbent dosage in heavy metal removal was also investigated. Adsorbent dosage plays a major role in the adsorption of contaminants, given that an increase in the adsorbent dosage creates more reaction sites for adsorption [30]. However, excessive use of adsorbent can worsen the cost-effectiveness during the water treatment process [31]. For this reason, the optimization of the adsorbent dosage of PAC and PAC-SDDC is needed.

Fig. 4 shows the improved removal of heavy metals at higher amounts of PAC at $\mathrm{pH}$ 7. While with increasing amounts of PAC from 5 to $30 \mathrm{~g} / \mathrm{L}$, increased Ni removal from 74.3 to $91.2 \%$, of $\mathrm{Zn}$ from 82.9 to $90.1 \%$ and of $\mathrm{Cr} 89.0$ to $89.5 \%$ were observed, the same increased PAC-SDDC amounts improved the removal from 65.6 to $81.7 \%$ for $\mathrm{Ni}$, from 72.7 to $85.0 \%$ for $\mathrm{Zn}$, and from 92.1 to $96.9 \%$ for $\mathrm{Cr}$, respectively. The result indicates that increasing the adsorbent dosage led to an enhancement in removal efficiency due to a greater surface area of adsorbent. Our result indicates that the optimization between adsorbent dosage and metal removal is needed for application to metal plating wastewaters. However, the less removal of metal was achieved when PAC-SDDC was used than PAC (Fig. 4). This result indicates that PAC is more effective for adsorption of $\mathrm{Cr}, \mathrm{Ni}$, and $\mathrm{Zn}$ compared to PAC-SDDC at least in neutral $\mathrm{pH}$ conditions, and might be due to that some of the reaction sites for metal adsorption in PAC are replaced with SDDC in PAC-SDDC adsorbent.

\subsection{Adsorption Isotherm}

Isotherms for heavy metal adsorption results were fitted independently to the Freundlich model, and fitting parameters are shown in Table 3 and Fig. S2. The goodness-of-fit $\left(\mathrm{R}^{2}\right)$ shows that the Freundlich isotherm was appropriate for adsorption of each heavy metal on PAC and PAC-SDDC except for Cr on PAC. When PAC was used as an adsorbent, Ni showed the highest $K_{f}$ and $1 / n$ values, and $C r$ showed the lowest $K_{f}$ and $1 / n$ values among three metals. However, using PAC-SDDC as an adsorbent, Cr showed the highest $K_{f}$ and $1 / n$ values, and Ni showed the lowest values. It was reported that the adsorption process is governed mainly by intra-particle diffusion, when the Freundlich intensity parameter $(1 / \mathrm{n})$ is $0.5[32,33]$. Thus, our result indicates that this phenomenon played a key role especially during the adsorption of $\operatorname{Cr}(1 / n=0.50)$ and $\mathrm{Zn}(1 / n=0.49)$ into PAC-SDDC.
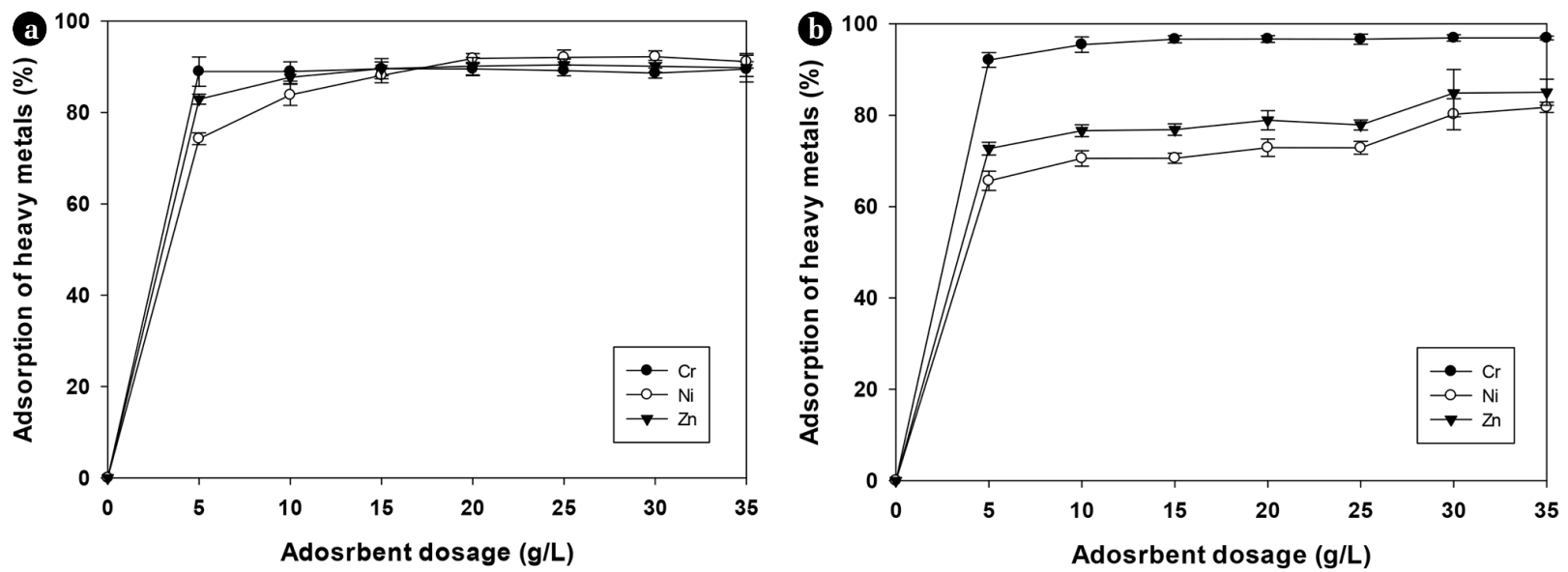

Fig. 4. Effect of adsorbent dosage on the adsorption of each metal using (a) PAC and (b) PAC-SDDC ([C $\left.\mathrm{C}_{0}\right]=50 \mathrm{mg} / \mathrm{L} ; \mathrm{pH}=7.0 ;$ temperature $=25^{\circ} \mathrm{C}$; time $=48 \mathrm{~h} ;[\mathrm{PAC}]$ and $[\mathrm{PAC}-\mathrm{SDDC}]=5$ to $35 \mathrm{~g} / \mathrm{L} ; \mathrm{n}=3$ ). 
Table 3. Freundlich Isotherm Fitting Parameters for Adsorption of 3 Metals on PAC and PAC-SDDC $\left(\left[\mathrm{C}_{0}\right]=50 \mathrm{mg} / \mathrm{L} ; \mathrm{pH}=7.0 ;\right.$ temperature $=25^{\circ} \mathrm{C}$; time $=48 \mathrm{~h} ;[\mathrm{PAC}]$ and $\left.[\mathrm{PAC}-\mathrm{SDDC}]=5-35 \mathrm{~g} / \mathrm{L}\right)$

\begin{tabular}{|c|c|c|c|c|c|}
\hline \multirow{2}{*}{ Adsorbent } & \multirow{2}{*}{ Metal } & \multicolumn{4}{|c|}{ Freundlich Coefficient } \\
\hline & & $K_{f}$ & $\left(\mathrm{mg} \mathrm{g}^{-1}\right)(\mathrm{mg} / \mathrm{L})^{-(1 / \mathrm{n})}$ & $1 / n$ & $\mathbf{R}^{2}$ \\
\hline PAC & $\mathrm{Cr}$ & & NA & NA & NA \\
\hline PAC & $\mathrm{Ni}$ & & $0.32 \times 10^{-3}$ & 0.72 & 0.986 \\
\hline PAC & $\mathrm{Zn}$ & & $0.80 \times 10^{-3}$ & 0.41 & 0.956 \\
\hline PAC-SDDC & $\mathrm{Cr}$ & & $4.13 \times 10^{-3}$ & 0.50 & 0.947 \\
\hline PAC-SDDC & $\mathrm{Ni}$ & & $1.35 \times 10^{-6}$ & 0.38 & 0.802 \\
\hline PAC-SDDC & $\mathrm{Zn}$ & & $0.20 \times 10^{-3}$ & 0.49 & 0.806 \\
\hline
\end{tabular}

\subsection{Effect of Initial pH on Adsorption}

To examine the effect of initial $\mathrm{pH}$ on adsorption, adsorption experiments were conducted under different $\mathrm{pH}$ conditions. Fig. 5 shows the effect of initial $\mathrm{pH}$ on heavy metal adsorption. As the $\mathrm{pH}$ increased, the adsorption removals of $\mathrm{Ni}$ and $\mathrm{Zn}$ were enhanced slightly whereas the $\mathrm{Cr}$ removal rate decreased significantly when PAC was used (Fig. 5(a)). Mishra and Patel [34] reported that the higher concentration and mobility of $\mathrm{H}^{+}$ions at acidic $\mathrm{pH}$ condition resulted in decreased adsorption of $\mathrm{Ni}$ and $\mathrm{Zn}$ due to competitive adsorption between metal and $\mathrm{H}^{+}$ ions. The surface of PAC can be mainly covered by $\mathrm{H}^{+}$ions when the $\mathrm{pH}$ is lower than the $\mathrm{pH}_{\mathrm{pzc}}$ value (10.7) of PAC. For this reason, the adsorption of metal cations ( $\mathrm{Ni}$ and $\mathrm{Zn}$ ) can decrease at lower $\mathrm{pH}$ value due to limited available binding sites on the PAC surface. However, when the $\mathrm{pH}$ increases, the competition between metals and $\mathrm{H}^{+}$ions can decrease, thus adsorption of $\mathrm{Ni}$ and $\mathrm{Zn}$ can increase.

The effect of $\mathrm{pH}$ on the adsorption can also be explained by surface complex formation theory (SCF), in which it is assumed that adsorption of metal ions and anions is mainly rely on $\mathrm{pH}$ and on the release of $\mathrm{OH}$ ions and $\mathrm{H}^{+}$[35]. Moreover, the increased $\mathrm{pH}$ can lead to binding of metals with $\mathrm{OH}^{-}$ions, which results in enhancement of hydrophobicity of metals. This has a positive effect on metal adsorption because hydrophobic contaminants are removed more readily than hydrophilic contaminants [36].

However, Cr adsorption in PAC decreased sharply by increasing pH (Fig. 5(a)); this result can be attributed to surface charge and shift in the ionic species in the solution [37]. In aqueous solution, $\mathrm{Cr}$ can exist in the form of $\mathrm{H}_{2} \mathrm{CrO}_{4}, \mathrm{HCrO}_{4}^{-}$and $\mathrm{Cr}_{2} \mathrm{O}_{7}{ }^{2-}$ ions under acidic $\mathrm{pH}$ conditions, but shifts to bivalent $\mathrm{CrO}_{4}{ }^{2-}$ as $\mathrm{pH}$ increases over 6.0 [38]. This bivalent ion $\left(\mathrm{CrO}_{4}{ }^{2-}\right)$ becomes dominant in alkaline $\mathrm{pH}$ condition, and therefore twice the number of sites of univalent charge is needed to neutralize [39]. As a result, the adsorption efficiency of $\mathrm{Cr}$ into adsorbent significantly decreases in general.

In contrast to PAC, PAC-SDDC showed a significantly different adsorption tendency for heavy metals. The adsorption removal of $\mathrm{Ni}$ and $\mathrm{Zn}$ were enhanced as the $\mathrm{pH}$ increased, but consistently lower than compared with PAC in all $\mathrm{pH}$ ranges, especially under acidic and neutral pH conditions (Fig. 5(b)).

The FT-IR spectrum in Fig. 2 shows that there was a decrease in the negatively charged hydroxyl functional group $(\mathrm{O}-\mathrm{H}$ band at $3,400 \mathrm{~cm}^{-1}$ ) after SDDC modification, which is mainly assigned to the carboxylic group O-H stretching in PAC [40, 41]. This functional group in PAC is known to have an effect on heavy metal removal (Eq. (7) and (8)) [42].
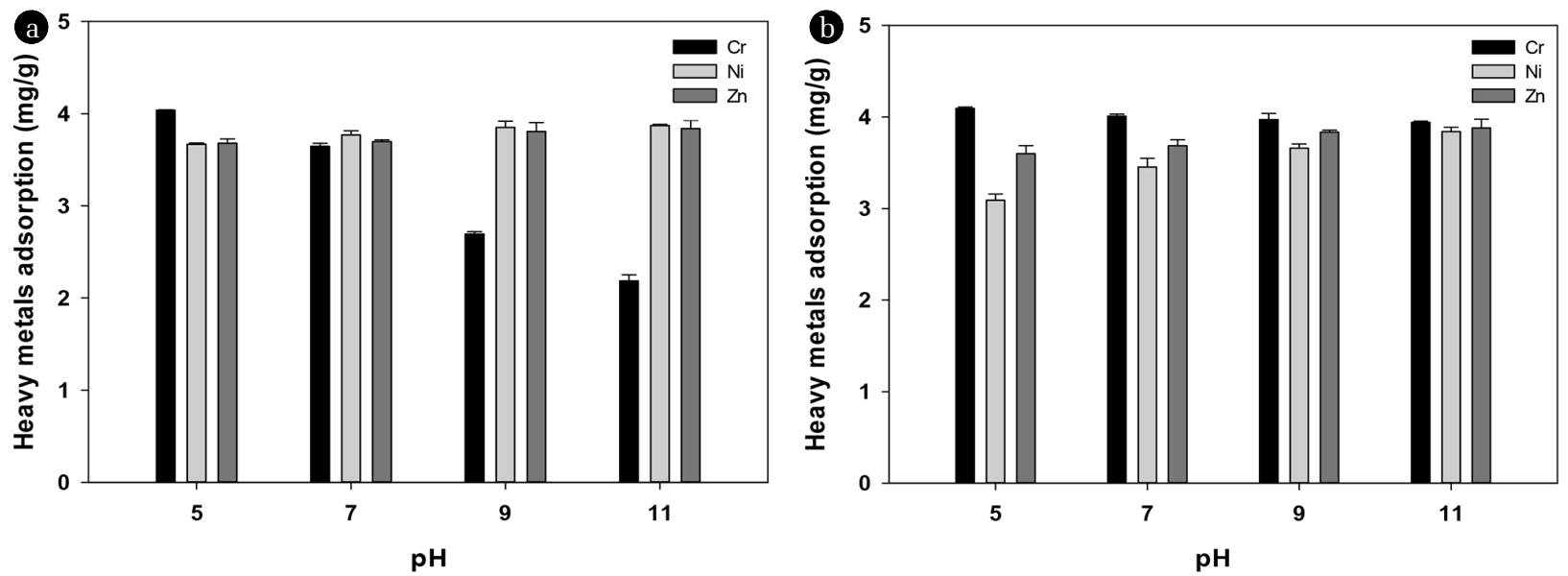

Fig. 5. Effect of initial $\mathrm{pH}$ on the adsorption removal of $\mathrm{Cr}$, Ni, and $\mathrm{Zn}$ using (a) PAC and (b) PAC-SDDC ([C $\left.\mathrm{C}_{0}\right]=50 \mathrm{mg} / \mathrm{L}$; $\mathrm{pH}=5$ to 11 ; temperature $=25^{\circ} \mathrm{C}$; time $=48 \mathrm{~h} ;[\mathrm{PAC}]$ and $[\mathrm{PAC}-\mathrm{SDDC}]=30 \mathrm{~g} / \mathrm{L} ; \mathrm{n}=3$ ). 


$$
\begin{gathered}
M^{n+}+n(-\mathrm{COOH}) \leftrightarrow(-\mathrm{COO})_{n} \mathrm{M}+n H^{+} \\
M^{n+}+n(-\mathrm{COOH})+n(-\mathrm{OH}) \leftrightarrow(-\mathrm{COO})(-\mathrm{OH})_{n} \mathrm{M}+n H^{+}
\end{gathered}
$$

Therefore, consistently lower adsorption of $\mathrm{Ni}$ and $\mathrm{Zn}$ on PAC-SDDC compared to PAC indirectly showed that SDDC was successfully adsorbed to the PAC surface, as the ligand can change $\mathrm{OH}$ groups in adsorbent to form ligand surface complexes [35].

However, the adsorption removal of $\mathrm{Cr}$ was affected only slightly by $\mathrm{pH}$ change, and increased significantly over the entire $\mathrm{pH}$ ranges in PAC-SDDC compared to PAC (Fig. 5(b)). This result can be explained by the complex formation between dithiocarbamate group in SDDC and Cr ion [16, 43]. It is reported that SDDC has versatile binding abilities and forms complexes with most transition metals, especially Cr species [44]. Through this process, negatively charged $\mathrm{Cr}$ can approach the adsorbent surface and form complexes with SDDC such as $\operatorname{Cr}(\mathrm{DDC})_{3}$ and $\mathrm{Cr}(\mathrm{DDC})_{2}$ (ODDC). In fact, due to this phenomenon, SDDC was applied for $\mathrm{Cr}$ species analysis including $\mathrm{CrO}_{4}{ }^{2-}$ and $\mathrm{Cr}_{2} \mathrm{O}_{7}{ }^{2-}[45$, 46]. Setiyanto et al. [47] also reported that $\mathrm{Cr}(\mathrm{DDC})_{2}(\mathrm{ODDC})$ is a majority product of reaction resulted from its higher dissociation energy $\left(\mathrm{Cr}(\mathrm{DDC})_{3}:-3.24 \mathrm{eV} ; \mathrm{Cr}(\mathrm{DDC})_{2}(\mathrm{ODDC}):-10.7\right.$ $\mathrm{eV}$ ) and chemical stableness. Monser and Adhoum [17] also reported enhancement of Cr removal by modified GAC (granular activated carbon) using SDDC.

Our results imply that PAC-SDDC can remove Cr more effectively than regular PAC especially at alkaline pHs. Since metal plating wastewater usually have alkaline $\mathrm{pH}$, PAC-SDDC can be effectively used to treat metal plating wastewater containing especially $\mathrm{Cr}$ without decreasing $\mathrm{pH}$.

\section{Conclusions}

In this study, the removal of $\mathrm{Cr}, \mathrm{Ni}$, and $\mathrm{Zn}$ metals using PAC and SDDC-modified PAC (PAC-SDDC) was investigated by examining the effects of time, adsorbent dosage, and initial $\mathrm{pH}$ on the adsorption kinetics of each adsorbent. PAC modification was confirmed by FT-IR, SEM, EDS, and physicochemical measurements. Increasing the time enhanced the adsorption of heavy metals. Both adsorption reactions followed a pseudo-second order reaction. The removal efficiency increased with adsorbent dosage. The removal of heavy metals using PAC followed the descending order of $\mathrm{Cr}>\mathrm{Ni}>\mathrm{Zn}$; for PAC-SDDC, the removal results were in the order $\mathrm{Cr}>\mathrm{Zn}>\mathrm{Ni}$. Adsorption removal results were in good agreement with the Freundlich isotherm, except for Cr adsorption on PAC. While PAC showed efficient removal of $\mathrm{Cr}, \mathrm{Ni}$ and $\mathrm{Zn}$ at acidic and neutral pHs, PAC-SDDC was effective especially $\mathrm{Cr}$ at alkaline $\mathrm{pH}$ conditions. Our results indicate that SDDC-PAC can be used to remove these alkaline metal plating wastewaters, especially $\mathrm{Cr}$ without decreasing $\mathrm{pH}$.

Further investigations of adsorption process optimization to apply PAC-SDDC to remove heavy metals from metal-plating wastewaters. The effects of pre-oxidation of cyanide using the alkaline chlorination or AOP process such as $\mathrm{UV}-\mathrm{H}_{2} \mathrm{O}_{2}$ process on adsorption are required.

\section{Supplementary Materials}

Table S1 shows the structure of SDDC and its physicochemical property. Experimental conditions of adsorption experiment are summarized in Table S2, and Table S3 shows the QA/QC results during heavy metal measurement using ICP-MS. Fig. S1 shows the pseudo-second order plot obtained by the linear regression method for the adsorption of each metal onto PAC and PAC-SDDC. Finally, Freundlich isotherm plot obtained by the linear regression for the adsorption of 3 metals onto PAC and PAC-SDDC is provided in Fig. S2.

\section{Acknowledgments}

This research was supported by Korea Ministry of Environment (MOE) as "Technologies for the Water Supply \& Sewerage Policy of Public Technology Program based on Environmental Policy (E416-00070-0605-0)". Thanks to Haley Suh for proofreading.

\section{References}

1. Kadirvelu K, Thamaraiselvi K, Namasivayam C. Removal of heavy metals from industrial wastewaters by adsorption onto activated carbon prepared from an agricultural solid waste. Bioresour. Technol. 2001;76:63-65.

2. Yeddou AR, Chergui S, Chergui A, et al. Removal of cyanide in aqueous solution by oxidation with hydrogen peroxide in presence of copper-impregnated activated carbon. Miner. Eng. 2011;24:788-793.

3. Smith MJ, Heath AG. Acute toxicity of copper, chromate, zinc, and cyanide to freshwater fish: Effect of different temperatures. Bull. Environ. Contam. Toxicol. 1979;22:113-119.

4. Tchounwou PB, Yedjou CG, Patlolla AK, Sutton DJ. Heavy metal toxicity and the environment. Molecular, clinical and environmental toxicology: Springer; 2012. p. 133-164.

5. Kuyucak N, Akcil A. Cyanide and removal options from effluents in gold mining and metallurgical processes. Miner. Eng. 2013;50:13-29.

6. Fu F, Wang Q. Removal of heavy metal ions from wastewaters: A review. J. Environ. Manage. 2011;92:407-418.

7. Aziz HA, Adlan MN, Ariffin KS. Heavy metals (Cd, Pb, Zn, $\mathrm{Ni}, \mathrm{Cu}$ and $\mathrm{Cr}(\mathrm{III})$ ) removal from water in Malaysia: Post treatment by high quality limestone. Bioresour. Technol. 2008;99:1578-1583.

8. Barakat M. New trends in removing heavy metals from industrial wastewater. Arab. J. Chem. 2011;4:361-377.

9. Hakizimana JN, Gourich B, Chafi M, et al. Electrocoagulation process in water treatment: A review of electrocoagulation modeling approaches. Desalination 2017;404:1-21.

10. Tangjuank S, Insuk N, Tontrakoon J, Udeye V. Adsorption of Lead(II) and Cadmium(II) ions from aqueous solutions by adsorption on activated carbon prepared from cashew nut shells. World Acad. Sci. Eng. Technol. 2009;52:110-116.

11. Barceló D, Petrovic M. Waste water treatment and reuse in the mediterranean region. Springer; 2011. 
12. Ahmad R, Hasan I. Efficient remediation of an aquatic environment contaminated by $\mathrm{Cr}(\mathrm{VI})$ and 2,4-dinitrophenol by XG-g-polyaniline@ZnO nanocomposite.J. Chem. Eng. Data 2017;62:1594-1607.

13. Say R, Birlik E, Denizli A, Ersöz A. Removal of heavy metal ions by dithiocarbamate-anchored polymer/organosmectite composites. Appl. Clay Sci. 2006;31:298-305.

14. Fu F, Zeng H, Cai Q, Qiu R, Yu J, Xiong Y. Effective removal of coordinated copper from wastewater using a new dithiocarbamate-type supramolecular heavy metal precipitant. Chemosphere 2007;69:1783-1789.

15. Bai L, Hu H, Fu W, et al. Synthesis of a novel silica-supported dithiocarbamate adsorbent and its properties for the removal of heavy metal ions. J. Hazard. Mater. 2011;195:261-275.

16. Abu-El-Halawa R, Zabin SA. Removal efficiency of Pb, Cd, $\mathrm{Cu}$ and $\mathrm{Zn}$ from polluted water using dithiocarbamate ligands. J. Taibah Univ. Sci. 2017;11:57-65.

17. Monser L, Adhoum N. Modified activated carbon for the removal of copper, zinc, chromium and cyanide from wastewater. Separ. Purif. Technol. 2002;26:137-146.

18. Zhou Q, Xing A, Zhao K. Simultaneous determination of nickel, cobalt and mercury ions in water samples by solid phase extraction using multiwalled carbon nanotubes as adsorbent after chelating with sodium diethyldithiocarbamate prior to high performance liquid chromatography. $J$. Chromatogr. A 2014;1360:76-81.

19. Monser L, Amor MB, Ksibi M. Purification of wet phosphoric acid using modified activated carbon. Chem. Eng. Process. Process Intensif. 1999;38:267-271.

20. Nasiruddin Khan M, Sarwar A. Determination of points of zero charge of natural and treated adsorbents. Surf. Rev. Lett. 2007;14:461-469.

21. Thajeel AS. Isotherm, kinetic and thermodynamic of adsorption of heavy metal ions onto local activated carbon. Aquat. Sci. Technol. 2013;1:53-77.

22. Onwudiwe DC, Ajibade PA. Synthesis and characterization of $\mathrm{Zn}(\mathrm{II}), \mathrm{Cd}(\mathrm{II})$, and $\mathrm{Hg}(\mathrm{II})$ Alkyl-aryl dithiocarbamate: X-ray crystal structure of $\left[\left(\mathrm{C}_{6} \mathrm{H}_{5} \mathrm{~N}(\right.\right.$ et $\left.) \mathrm{CS}_{2}\right) \mathrm{Hg}\left(\mathrm{C}_{6} \mathrm{H}_{5} \mathrm{~N}(\right.$ butyl $\left.\left.) \mathrm{CS}_{2}\right)\right]$. Synth. React. Inorg. Met.-Org. Nano-Metal Chem. 2010;40:279-284.

23. Onwudiwe DC, Arfin T, Strydom CA, Kriek RJ. A study of the thermal and AC impedance properties of $\mathrm{N}$-phenyldithiocarbamate complexes of $\mathrm{Zn}(\mathrm{II})$. Electrochim. Acta 2013;109:809-817.

24. Chingombe P, Saha B, Wakeman R. Surface modification and characterisation of a coal-based activated carbon. Carbon 2005;43:3132-3143.

25. Gomes PC, Fontes MP, da Silva AG, de S Mendonça E, Netto AR. Selectivity sequence and competitive adsorption of heavy metals by Brazilian soils. Soil Sci. Soc. Am. J. 2001;65:1115-1121.

26. Ho Y-S, McKay G. Pseudo-second order model for sorption processes. Process Biochem. 1999;34:451-465.

27. Yuh-Shan H. Citation review of Lagergren kinetic rate equation on adsorption reactions. Scientometrics 2004;59:171-177.

28. Ho Y, McKay G. A comparison of chemisorption kinetic models applied to pollutant removal on various sorbents. Process Saf. Environ. Prot. 1998;76:332-340.
29. Kumar PS, Vincent C, Kirthika K, Kumar KS. Kinetics and equilibrium studies of $\mathrm{Pb}^{2+}$ in removal from aqueous solutions by use of nano-silversol-coated activated carbon. Braz. J. Chem. Eng. 2010;27:339-346.

30. Salam MA, Al-Zhrani G, Kosa SA. Simultaneous removal of copper(II), lead(II), zinc(II) and cadmium(II) from aqueous solutions by multi-walled carbon nanotubes. C. R. Chim. 2012;15:398-408

31. Snyder SA, Adham S, Redding AM, et al. Role of membranes and activated carbon in the removal of endocrine disruptors and pharmaceuticals. Desalination 2007;202:156-181.

32. Lyubchik SI, Lyubchik AI, Galushko OL, et al. Kinetics and thermodynamics of the $\mathrm{Cr}$ (III) adsorption on the activated carbon from co-mingled wastes. Colloid. Surf. A. Physicochem. Eng. Asp. 2004;242:151-158.

33. Schneider R, Cavalin C, Barros M, Tavares C. Adsorption of chromium ions in activated carbon. Chem. Eng. J. 2007;132:355-362.

34. Mishra P, Patel R. Removal of lead and zinc ions from water by low cost adsorbents. J. Hazard. Mater. 2009;168:319-325.

35. Stumm W. The inner-sphere surface complex: A key to understanding surface reactivity. ACS Publications; 1995.

36. Moreno-Castilla C. Adsorption of organic molecules from aqueous solutions on carbon materials. Carbon 2004;42:83-94.

37. Harter RD, Naidu R. An assessment of environmental and solution parameter impact on trace-metal sorption by soils. Soil Sci. Soc. Am. J. 2001;65:597-612.

38. Mier MV, Callejas RL, Gehr R, Cisneros BEJ, Alvarez PJ. Heavy metal removal with mexican clinoptilolite: Multi-component ionic exchange. Water Res. 2001;35:373-378.

39. Pandey P, Sharma S, Sambi S. Kinetics and equilibrium study of chromium adsorption on zeoliteNaX. Int. J. Environ. Sci. Technol. 2010;7:395-404.

40. Chen JP, Wu S. Acid/base-treated activated carbons: characterization of functional groups and metal adsorptive properties. Langmuir 2004;20:2233-2242.

41. Winter A. Organic chemistry I for dummies. John Wiley \& Sons; 2005

42. Mishra S. Adsorption-desorption of heavy metal ions. Curr. Sci. 2014;107:601-612.

43. Crompton TR. Determination of metals and anions in soils, sediments and sludges. CRC Press; 2001.

44. Zhen H-b, Xu Q, Hu Y-y, Cheng J-h. Characteristics of heavy metals capturing agent dithiocarbamate (DTC) for treatment of ethylene diamine tetraacetic acid-Cu (EDTA-Cu) contaminated wastewater. Chem. Eng. J. 2012;209:547-557.

45. Moghimi A. Solid phase extraction and determination of Chromium species using multiwalled carbon nanotubes by solid phase extraction: Flame atomic absorption spectrometry (FAAS). Afr. J. Pure Appl. Chem. 2013;7:146-156.

46. Kaur V, Malik AK. Speciation of chromium metal ions by RP-HPLC. J. Chromatogr. Sci. 2009;47:238-242.

47. Setiyanto H, Muhida R, Kishi T, et al. First-principles calculations for chemical reaction between sodium diethyldithiocarbamate and transition-metal $(\mathrm{Cr})$ atom to produce $\mathrm{Cr}(\mathrm{DDC})_{3}$ and $\mathrm{Cr}(\mathrm{DDC})_{2} \mathrm{ODDC}$. Jpn. J. Appl. Phys. 2006;45:L1103. 